\title{
SACERDOTES SIGLO XXI DESDE LA FIDELIDAD
}

Autor: Alonso Morata Moya. Sacer-
dote Operario. Director del IVMA y

Autor: Alonso Morata Moya. Sacer-
dote Operario. Director del IVMA y de la Revista Seminarios.

\section{DOI: https://doi.org/10.52039/seminarios.v47i162.933}

\section{Introducción}

No sé si es buena idea comenzar un estudio que pretende ser serio con un breve cuento. Sobre todo porque puede dar la sensación de que, de nuevo, nos introducimos en la religiosidad ficción, pero la parábola siempre ha sido camino de entendimiento de la realidad que se nos hacía ardua por abstracta. Ésta que relata Joan Chisttiter me parece además muy oportuna para entrar de lleno en el tema que quiero exponer

«Cuenta la historia que un día el abad Lot fue a ver al abad José y le dijo: "Padre, en lo que puedo, observo una regla sencilla, hago pequeños ayunos, practico algo de oración y meditación, guardo silencio y, en la medida de lo posible, procuro mantener limpio mi pensamiento. ¿Qué más debería hacer?" El viejo monje se puso en pie, alzó las manos hacia el cielo, y sus dedos se convirtieron en diez antorchas 
llameantes. Entonces dijo: “¿Por qué no te transformas en fuego?”»1. La primera enseñanza de ella es la de que no podemos estar guardando las brasas de una piedad personalista que sólo nos calienta a nosotros mismos, sino que hay que avivar el rescoldo que queda para dar calor a todos los circunstantes, y para eso es necesario arder, transformarse en fuego, ¿gastarse?

En el año 2000 y en los precedentes nos ha dado por acuñar tér-

Hay preguntas que brotan de nuestra inquietud evangelizadora minos como "sacerdotes del o para el tercer milenio", "el sacerdote del futuro", o por hacernos preguntas del tipo "¿qué vocaciones para este mundo nuevo?; ¿habrá respuestas a la llamada en esta sociedad cambiante?" No cabe duda de que son preguntas o rótulos que tienen como causa una inquietud, la que como cristianos (sacerdotes, religiosos o laicos), preocupados por la extensión del reino, nos hacemos al analizar las realidades en las que nos desenvolvemos.

En primer lugar, hemos de decir que cuando hacemos este análisis lo basamos en nuestras posibilidades, en la medida de nuestras fuerzas y me parece necesario que nos situemos en otra dimensión, aunque sin olvidar en donde nos encontramos y qué clase de sociedad es ésta de la que formamos parte. La dimensión en la que hemos de situarnos es en una lectura creyente de la historia del hombre, en saber que es el mismo Dios el que la dirige y que lo que ahora sucede es un mensaje que nos está lanzando para que volvamos a la escucha de lo que él quiere para y del hombre. Esto está ya dicho de una vez por todas en la Sagrada Escritura.

En segundo lugar, no hemos de preocuparnos por hacer que la 'función profética' se convierta en un adivinar el futuro, como si de pases mágicos se tratara. El futuro se asienta sobre una dinámica de la Iglesia, que avanza, que va en camino, proyectando su luz en la historia del hombre. La profecía en este asunto está unida a la fidelidad al momento, abiertos a los signos que en él se presentan. Ser capaces de maravillarse y dejarse conducir: No querer que todo esté predeterminado y suceda como lo teníamos previsto. Dios nos hace ver, de vez en cuando, que la historia la lleva él y... nos sorprende. Cuando esto nuevo sucede «Es como cuando la melodía te viene a buscar. No eres tú el que va a buscar la melodía. Cuando esto ocurre es algo hermoso.

${ }^{1}$ CHITTISTER, J. El fuego en estas cenizas, Sal Terrae, Santander, 1999, p.53. 
Y cuando ocurre no puedes por menos que seguirlo». Así describe Benigni su sentimiento sobre 'La vida es bella', la película que le valió el Óscar de Hollywood 99 a la mejor película extranjera. Péguy nos dice también: «La primera será la mejor, porque no sabe, porque aún está llena de estupor [...]. Es un problema de genio, es más, todo su problema temporal está ahí: ganar, si se puede, [...] pero esencialmente no perder estupor ni novedad, no perder la flor» ${ }^{2}$. No perder novedad. Ahí está parte del secreto de lo que quisiera exponer en este trabajo. Pedir ser capaces de acoger en nosotros la novedad del mensaje de Jesús y de lo que significa ser siempre ministro (servidor) de un evangelio (buena nueva) que no puede quedar anclado ni secuestrado por las formas (ni las llamadas progresistas, ni las llamadas retrógradas); que se significa siempre por estar en el punto de sazón, por ser iluminador de la vida en cada tiempo, en cada momento de la historia. Esa historia que es dinámica.

En tercer lugar, y por cabalgar sobre el dinamismo de la historia, es preciso asumir el tono de la sociedad en la que vivimos, con sus luces y sus sombras, precisamente para intentar que el lenguaje y las imágenes a través de las cuales presentamos el mensaje de Jesús sean entendidas y muevan a los hombres y mujeres de este tiempo. Y, si eso es función de todo cristiano, lo es de manera especial de los sacerdotes o personas que tienen una modalidad de vocación que, de por sí, está dedicada de pleno a la transmisión de esa buena nueva con palabras y con la vida. En la tarea de la evangelización el objetivo no es hacer juicios, sino ser testigos.

\section{¿Por qué no hay vocaciones? ¿Qué vocaciones para hoy?}

Es posible que la primera respuesta que tengamos que dar a la pregunta del epígrafe es la de que no hemos caminado hacia una forma nueva de concebir el sacerdocio, la vida religiosa, no hemos hecho todavía el despegue de una forma muy concreta de concebir la Iglesia, y debemos situarnos de otra manera en este mundo, precisamente para cumplir la función que Dios nos confía. Reconozco que esto no es fácil y que es

${ }^{2}$ PEGUY, CH., Véronique. Dialogue de l'historie et de l'âme charnelle. 30 Giorni, 8 (99) p.52. 
490 Quizás no hemos sintonizado aún con el reloj del Vaticano II

necesario realizar un proceso de cambio profundo desde la persona y desde la institución Iglesia. El concilio Vaticano II supuso una puesta en hora del reloj de la Iglesia, pero ;hasta que todos lo sintonicemos...! Han pasado años, se han multiplicado los documentos y aún no hemos logrado ajustar el ritmo. Puede que echemos demasiado la mirada hacia atrás, sin darnos cuenta de que hemos de alcanzar nuevos predios, para saber la fertilidad de esos campos sin roturar: nueva juventud, nuevos objetivos, nuevas debilidades y carencias, nuevas gentes que necesitan esa palabra de salvación. No se trata de hacer un arreglo de apariencia (de fachada), la conversión (el cambio) se ha de realizar desde lo profundo. Quizás hay intereses creados o son muchos los registros que hay que poner al día.

Es posible que tengamos que hacer un recorrido sobre nuestro camino de estos años, para entender algo más el lenguaje nuevo y las nuevas formas a las que hemos de dar respuesta. Me ha impresionado este párrafo de Charles Peguy: "Es porque nuestro corazón ha querido profundizar en el mismo camino y no porque se deba a una evolución ni a un cambio de opinión, (por lo que hemos hallado la senda del cristianismo). No la hemos hallado por haber tomado el camino de vuelta, sino por haber llegado hasta el final. Y por eso es necesario que una parte y la otra lo sepan bien, no renegaremos jamás de ningún átomo de nuestro pasado"3. Sobre todo es importante porque asume que todo su caminar ha sido hacia el encuentro con Dios, incluso los pasos dados fuera de su aparente presencia.

Nos situamos además en una eclesiología de comunión como impulsó el Vaticano II, en una Iglesia de hermanos que saben distribuirse los 'servicios' más que las 'dignidades' y sabemos que los servicios son variados y muy necesarios. Éstos se concretan en la vocación cristiana en las tres modalidades: laicos, vida religiosa, sacerdotes.

\section{Entre dos mundos: el que vivimos de niños y el de ahora}

Nos encontramos entre una exigencia anacrónica y una permisividad antieducativa: La mayoría de nosotros nacimos en una sociedad de carencia y nos encontramos en la sociedad de la opulencia y el consumo. Dos actitudes diferentes pueden nacer: pensar que nuestra diná-

\footnotetext{
${ }^{3}$ Ibidem, p. 51.
} 
mica de crecimiento es la única válida (no prestar oídos a la nueva sociedad emergente), o también (frecuente más en abuelos que en padres) pensar que ya hemos sufrido nosotros bastante y hay que ahorrar penalidades y contrariedades a los demás (sobre todo a 'los demás' que son más nuestros). Nos situaríamos así entre una exigencia 'anacrónica' y una permisividad 'antieducativa'. Es necesario el equilibrio suficiente que nos permita digerir el pasado, asimilarlo y exigir en el presente el camino que lleve a constituir a la persona de hoy, con garantías de suficiente solidez.

Necesitamos caminar hasta esta época en la que nos encontramos y valorarla (lo que implica: no considerarla poseída del demonio, ni ocultar sus lacras y creer que es la más maravillosa de todas épocas de la historia) ; vivir en este espacio y este tiempo. Hacer la lectura realista de lo que nos rodea, (también de los fieles cristianos) y buscar lo que es hoy la respuesta a la vida y desde la vida, sin dejar de ser cristiano, más aún, porque se es cristiano. Esta es época en la que el amor salvador de Dios sigue estando pendiente de nosotros. Somos personas que han ido descubriendo el bienestar (y mediante un proceso no siempre armonioso y sosegado) y afrontamos el peligro de acomodarnos a este bienestar sin juicio o percibir sólo sus rasgos negativos.

Hay otra juventud. El educador, el sacerdote ha de estar en constante tensión para madurar con los más jóvenes de la comunidad, sin los que no hay vida futura. Y esa es una juventud deudora de su nacimiento en plena sociedad de consumo, en la que domina la inestabilidad y lo provisorio ("todo pasa, nada es eterno" o el "carpe diem" como filosofía de la volatilidad del ser). Y hay que amar el mundo de los jóvenes tal como es y caminar con ellos para ayudarles a madurar de manera nueva. Y saber que a esta juventud (por lo general) le es muy difícil tomar decisiones y compromisos definitivos (al menos a la manera como los hacíamos nosotros). Juventud, en parte, superprotegida, guardada y resguardada (y en parte, expuesta a todos las influencias incontroladas). Quizás por eso prolonga demasiado la adolescencia (síndrome de 'Peter Pan' = confundir libertad con ausencia de vínculos. Prometer no hacerse nunca mayor $\left.{ }^{4}\right)$. En contraste está ese otro

${ }^{4}$ MARTÍNEZ CORTÉS, J., Familia, religión, sociedad: ¿hacia una sociedad de «eternos adolescentes»? MISIÓN JOVEN, 269 (99) pp. 13-22.

Caminar hasta llegar a este punto de la historia 
entrañable personaje de ficción, El Principito que va madurando a base de encuentros que le llevan a asumir su papel, la responsabilidad con la rosa. Lo cual no le impide darnos una visión del mundo desde dentro, desde lo más profundo: «Solo se ve bien con el corazón. Lo esencial es invisible a los ojos» ${ }^{5}$. $\mathrm{O}$ un síndrome de inconsistencia que algunos psiquiatras han definido como "déficit de narcisización" y se manifiesta por la inseguridad, el deseo de aprobación, el buscar garantías, llamar la atención, poca claridad de pensamiento, inestabilidad de afectos, miedo a la soledad y ante cualquier dificultad. Y, todo ello, según los mismos psiquiatras que lo detectan, no es patología sino déficit de maduración.

Lo primero, pues que se nos exige es que el sacerdote (y el cristiano en general) sea hombre de su tiempo y acepte a las gentes como son (o como los hemos hecho). El proceso de evolución ha sido muy distinto, por eso cabría hacer una disección en dos columnas, aunque los rasgos no siempre son puros.

\section{Rasgos para un perfil del contraste}

I. Lo racional y su contrapunto emotivo. Fuimos educados en la racionalidad del silogismo ${ }^{6}$. Premisa mayor, premisa menor y conclusión. A muchos la poesía les parecía una pérdida de tiempo. Todo lo metafórico (por pender del mundo afectivo) era sospechoso de irreali-

Equilibrar lo emotivo y lo racional dad, muy apropiado para las noches de luna y el canto de los sentimientos. La mayoría de nosotros tiende a actuar por lógica (aunque la lógica le falle muchas veces). Como conclusión de las premisas puestas [por esta razón puede ahogarnos el desaliento cuando ponemos todos los medios para que tenga éxito nuestra tarea (santa tarea) y las cosas no salen cuando ni como habíamos planificado]. No es extraño que hayamos tenido miedo a nuestro afectos, incluso que hayamos pensado que eran signo de debilidad.

También podemos caer en el otro extremo: actuar desde los sentimientos y jugar con ellos, dejando fuera cualquier tipo de control

5 SAINT-EXUPERY, A., Le Petit Prince, E. Sainz Editores, S.A. México, 1994, p.96.

${ }^{6}$ Lo racional puede llevar a dureza, inmovilismo, rigidez, fanatismo intelectual (Nota del Autor). 
maduro. Hay peligro de mensaje ambiguo. (Tendemos a reaccionar o desde la frialdad y seguridad del pensamiento racional, claro y distinto, en un mundo en el que la razón ha perdido todo su prestigio, en el que el pensamiento débil ha tomado carta de naturaleza, las ideas absolutas están proscritas (quizás todas las ideas); o simplemente desde un sentimiento siempre hambriento de afectos, deudor de acogida y aceptación, mendigando comprensión) 7 .

En los jóvenes hay menos ambigüedad: predomina el polo afectivo. Privilegian las relaciones interpersonales a costa del trabajo o de los estudios (¿por qué creéis que pierden la vida en las riberas del viernes al sábado, sin más comunicación que la del contacto - roce físico?). Este mundo seco y frío en el que viven no tiene más contestación que responder, tomar decisiones a "golpe de corazón". El criterio más válido es "yo aquí me encuentro bien". Yo individuo estoy caliente, ¿qué me importan los otros?. Esta actitud es peligrosa para los mismos jóvenes porque les puede hacer perder el sentido de cualquier compromiso personal.

Lo importante es ver que los dos elementos son imprescindibles para el funcionamiento equilibrado de la persona. Acentuar sólo uno de ellos impide la integración de la persona.

\section{La visión global, y lo provisional y pequeño como filosofía} de la vida: Aprendimos a ver las cosas en su globalidad, nos acostumbramos a una visión panorámica y de conjunto, a no tener prisa por acabar la obra, ya que no era sólo de nosotros, que lo importante era continuar la tarea que otros habían iniciado y que no sabíamos quién la acabaría, pero tendría buen fin. Muy imbuidos de lo que san Pablo nos dice en I Cor 4, 7: "No cuenta ni el que planta, ni el que riega; Dios, que hace crecer, es el que cuenta". Convencidos de pertenecer a una obra que nos sobrepasa en el espacio y en el tiempo. Nos encontramos con que hoy día lo que cuentan son los hechos con resultados rápidos y palpables: vemos con admiración la generosidad de muchos jóvenes que marchan, incluso con peligro de su vida, a lugares en conflicto y a quienes no les importa vivir en carencia... Con tal de que sea por tiem-

${ }^{7}$ El contraste del predominio de lo emotivo está en generar inconsistencia, falta de control, pensamiento débil. 
Sensibilidad ante lo concreto, no ante problemas estructurales

De un mundo cerrado a un mundo plural po limitado. Ni gustan, ni suelen comprometerse en tareas que exigen mucho tiempo y menos aún que sean encargos de por vida (¡Hasta ahí podríamos llegar!). Hay sensibilidad hacia los problemas concretos y puntuales, pero no hacia los problemas estructurales. Atrae lo que está ahí. Al alcance de nuestra acción, pero no preocupa integrarlo en un conjunto, en un todo de mayores vuelos y con estructura global. Falta sentido de la utopía. Queda demasiado lejos, como una metáfora de lo irrealizable (como forma de vida no es ajeno a nuestros jóvenes el ¡cuán largo me lo fiáis! de D. Juan Tenorio). Esta postura nos está diciendo algo; y podíamos preguntarnos si no sería lo más educativo, aprender también nosotros a caminar desde lo pequeño a lo global. No se puede acompañar a nadie en su caminar, si no se va por el mismo camino, ir por arriba o por abajo da otra perspectiva, aunque a veces sea necesario tener esa otra visión.

III. De un mundo uniforme a un mundo plural: El ambiente en el que nos educamos tendía a la univocidad: política, social, económica, religiosa. Un mundo cerrado. Fácilmente etiquetable. Todo se presentaba bajo un prisma único. Los valores estaban ahí y ni siquiera había tentación de discutirlos, porque aquel que tuviera tal tentación era rápidamente anatematizado. Había interés por el mundo religioso y éste se veía acompañado de una suficiente cultura y formación en la fe (al menos más amplia que la actual); la utopía nos abría caminos nuevos, aunque dicha utopía se mantuviese dentro de parámetros religiosos. Y ¿en qué hemos desembocado? Nuestros jóvenes viven y se educan en un pluralismo no sólo cultural, sino de valores. Con una moral convivencial, sincretista y con poca claridad acerca de lo bueno o malo. Con ausencia de sentido de culpa (el sentimiento de culpa fue rasgo de nuestros años mozos). A lo más uno se equivoca, pero pecar... ¿eso qué es?

Nosotros ¿sabíamos más cosas? Puede que en la teoría les sacásemos alguna ventaja. Estábamos en una cultura especulativa. Y, de pronto, nos encontramos con que "vivir es experimentar" y "quien no experimenta no vive". Se prima lo inmediato y lo presente, la fragmentación está a la orden del día. Lo provisional se convierte en lo único que merece la pena. No se distingue entre causa y efectos.

$\mathrm{Y}$, sin embargo, todo este sentido de experiencia es positivo, porque nos hace tomar mayor contacto con lo real, más dialogantes y 
comprensivos, con un talante más abierto y más evangélico; y nos ayuda a descubrir que fe no es conocer mucho, sino vivir intensamente en Dios, ponerse en sus manos, como Él se pone en las nuestras. Nos introduce en una actitud nueva y rica: vivir el detalle de Dios en el cada día y desde ángulos diferentes.

IV. En lo referente al lenguaje. Para nosotros éste era más bien claro y de significado directo. La parcelación de la realidad respondía bastante a la expresión de la misma realidad, sabíamos qué significaban palabras como 'amor', 'felicidad', 'entrega'..., al menos oficialmente. En este momento el lenguaje está secuestrado y hay quienes lo manipulan. Las cosas ya no significan algo determinado, ni siempre lo mismo, su sentido es variable, según las circunstancias; hay inseguridad semiótica y semántica; se sabe leer, pero no ajustar bien la imagen del significado. Es un analfabetismo de segundo grado. A. López Quintás dice a este respecto que "no se piensa bien, ni se tiene pensamiento de largo alcance. Se piensa mal a causa de la manipulación y hay que descubrir los pases del ilusionismo que efectúa continuamente el manipulador para ejercitar su poder de engaño. Estamos en una sociedad desconcertada y desvalida. Sociedad que practica el intrusismo y el reduccionismo. Sobre todo del lenguaje". Hay que desenmascarar al que manipula.

"El manipulador lleva a cabo toda suerte de escamoteos con términos y esquemas para que la gente asuma convicciones a las que jamás llegarían a través de un razonamiento detenido y correcto. Todo parece limpio en el proceder del manipulador. En realidad no engaña; simplemente manipula, altera el orden de los conceptos y esquemas mentales y consigue que las gentes saquen por su cuenta conclusiones falsas, bien ajustadas a los intereses del falsificador"8.

Vivimos en este mundo de contrastes entre lo que fuimos y lo que estamos llamados a ser. Vemos la llamada de lo pequeño y que desde aquí hemos de ser testigos. Asumiendo todo lo que hemos recibido no hemos de decir simplemente que hacen falta hombres y mujeres de hoy, sino que nosotros somos esos hombres y mujeres de hoy, y de la Iglesia y el mundo de hoy, (aunque estemos necesitando el recambio
Vivir al

detalle de

495

Dios en el cada día

La ambi-

güedad del lenguaje

${ }^{8}$ LÓPEZ QUINTÁS, A., La revolución oculta, PPC. MADRID 1998, pág. 177. 
Testigos de

la Iglesia

de hoy en

este mundo

de la juventud). Testigos sin duda alguna. Pero ¿qué testigos?. Y ¿de qué manera testigos? (Hay en este momento en algunas instituciones y, no dudo de su buena fe e intención, una tendencia a formar a los nuevos 'adeptos' con métodos y en filosofías de un pasado seguro, en coordenadas de otros tiempos. Cierto que a sus puertas están llamando cada vez más jóvenes, y yo me hago la pregunta de Cencini en la conferencia dada en la reunión de Superiores mayores: "¿Qué vocaciones para una vida consagrada renovada? ¿qué tipo de vida consagrada para vocaciones 'nuevas'? 9 Veremos que el documento 'Nuevas vocaciones para una nueva Europa", subraya el carácter de vocación como rasgo de la vida.

Importa que todo esto no nos lleve a posturas negativas. Sí a leer la realidad tal como es. Durante mucho tiempo hemos estado pidiendo a la Iglesia que se ponga al día, y creo que lo importante es situarse en el mundo con sus miserias y sus grandezas, sin hacer abstracción de lo que hay. Ser cronista de lo que observamos. Vemos con claridad que son necesarios hombres y mujeres de este tiempo que den una respuesta sólida a los interrogantes que tiene el joven (hombre/mujer) de hoy (sobre todo, a aquello que se siente como lastre). Vivir su vida asentados en una tarea concreta de evangelización que se inserta en la tarea más amplia del plan de salvación de Dios.

Y ahora concretamos más. En este mundo y para este mundo ¿qué sacerdotes?

\section{Sacerdotes para el futuro}

En este mundo y desde esta realidad, son necesarios nuevos

Tener el oído abierto a la escucha de los gritos del hombre, hoy erdotes. ¿Qué rasgo fundamental les pediríamos? La palabra está clara: Ser pastores. [Hemos de superar la confusión que hay entre el cómo debe ser y el cómo debe actuar el sacerdote]. Estar pendientes con caridad pastoral de las necesidades de la comunidad. Escuchar los gritos de las carencias que, pese a vivir en esta sociedad que hemos llamado opulenta, angustian a las personas de nuestro entorno y, en concreto, de nuestra sociedad española del siglo XXI. "El contenido esen-

${ }^{9}$ CENCINI, A., SEMINARIOS, 153 (99) pp. 265-291. 
cial de la caridad pastoral es la donación de sí, la total donación de sí a la Iglesia, compartiendo el don de Cristo y a su imagen"10.

Para esto es preciso ser signo de contracultura. Dar 'la nota'. Una nota diferente a la que busca de forma monocorde el habitante de la sociedad europea, del primer mundo, de un mundo que puede llegar a reducir al hombre a sólo apariencia. Poco puede hacer como signo y llamada un sacerdote preocupado, como el resto de sus vecinos, por el tener, acaparar poder o placer.

Esfuerzo por recrear y hacer visible una nueva imagen de Dios que responda a lo más original que se nos ha revelado en Jesús de Nazaret y sintonice de verdad con las ansias, intuiciones y exigencias de nuestro tiempo.

Para trazar un perfil creíble del sacerdote para el tercer milenio, creo que necesitamos que el sacerdote tenga: una formación teológica seria; que sepa orar al Dios de Jesús; que se distinga por su caridad pastoral, perfil que le define y centro de vida; asumir el celibato como medio para ser pastores; la pobreza como sintonía de contraste.

Todo ello nos lleva a descubrir y hacer que descubran que no es el hacer cosas sino el ser significativo de otra forma de hacer lo que distingue al sacerdote de hoy en camino al futuro:

\section{Necesidad de formación profunda}

Ser maestro, para dar luz en el camino a los hombres y mujeres de esta época (nuevo tono de la formación): Es preciso no apoyar una imagen de Dios que resulta cada vez menos visible y creíble. Saber y aceptar, porque Dios así lo quiere además, que los fenómenos humanos los explican las ciencias y la hipótesis Dios es superflua como explicación: «De un mundo sacral, continuamente traspasado por fuerzas ultramundanas que, o bien surgían del abismo para tentar, hacer daño y provocar enfermedades, o bien bajaban del cielo para ayudar, salvar y curar, hemos pasado a un mundo secular, regido por leyes inmanentes con

\footnotetext{
10 Pastores dabo vobis, $\mathrm{n}^{\circ}$ 23, Comisión Episcopal de Seminarios y Universidades, p. 58.

11 TORRES Q., A., Por el Dios de mundo, en el mundo de Dios, Sal Terrae, Santander 2000, pág. 92.
}

Formación y visión "ilustrada" de la realidad 
autonomía propia» ${ }^{11}$. Esto quiere decir que ya no podemos atribuir a Dios o al demonio ciertos aconteceres mundanos. La cultura general, expandida desde los medios de comunicación, muestra constantemente esta otra dimensión secular. Más que creer que estábamos hechos a imagen y semejanza de Dios, hemos creado un "ídolo" a nuestra imagen y semejanza que se desvanece a medida que van aclarándose los caminos del mundo, en el mundo de Dios.

También nos llama la atención sobre la manera de leer la Biblia.

La fe es la misma, la teología que la explica ha cambiado

El sacerdote debe ser competente en cuestiones religiosas No nos está permitido ignorar los grandes progresos que en el estudio de la Biblia se han logrado en los últimos tiempos. Descubrimientos que no rebajan su valor de palabra revelada, sino que la sitúan en su contexto más iluminador: nos hacen ver que muchas afirmaciones de la Biblia hay que comprenderlas y expresarlas de otro modo: "La fe que se nos trasmite a través de esa tradición es tan válida como siempre; la teología con la que se explica no siempre lo es. Confundir la una con la otra puede resultar mortal para la primera, porque, al no poder aceptar esa teología, muchas personas en la cultura actual se creen obligadas a rechazar la fe. Lo que se dice «arrojar el niño con el agua de la bañera»"12. (Lo que cambia es el agua: la teología que valió en un momento; lo que tiene que quedar es el niño: la fe medio de salvación y de encuentro). Y en lugar de empeñarnos en la literalidad de una explicación teológica del momento, nos hemos de dedicar a hacer más inteligible esa palabra para los hombres del tiempo presente, sin que tampoco esta explicitación hipoteque el futuro ${ }^{13}$.

Que es una tarea importante, porque afecta a la interpretación de los fundamentos: exige preparación y responsabilidad. La formación y la vida espiritual son imprescindibles para el sacerdote de hoy que es también para el mañana y tiene que abrir caminos a los nuevos, y para ello hay que tener una conciencia teológica adecuada a la propia cultura. Lo importante para el que se acerca al sacerdote es que éste sea competente en cuestiones religiosas. Y esto ha de ser el objeto de nuestro estudio: prepararse en teología. "Me parece suicida seguir manteniendo esa política por la que quienes se incorporan a comunidades religiosas dedican lo mejor de su trabajo intelectual a estudiar una

12 Ibidem, pág. 94.

13 TORRES QUEIRUGA, A., opus cit. pág. 95. 
carrera ajena a la teología". Puede que hace unos años creyéramos que la preparación en ciencias, matemáticas, lingüística, etc. era de todo punto necesaria, en las actuales circunstancias, sería como si el que va a ser médico, se preparara en física cuántica, en sociología, y poco en medicina.

Si la vivencia, comprensión y testimonio de la fe se asume como el eje y dedicación fundamental, en torno a éste tiene que girar todo: también los estudios. Lo contrario indicaría que nos tomamos poco en serio eso de configurar nuestra vida como vivencia, testimonio, transmisión y educación de la fe. Para ser maestro, de la forma especial que lo ha de ser el sacerdote para la comunidad, trasmitir vida más que conocimientos, el estudio y la oración son importantes. Siempre en actitud contemplativa

\section{Descubrir la oración}

\section{1) Orar al Dios de Jesús}

En realidad la vocación a consagrarse no es solamente a ser utópico, a tener ideales nobles, sino que esta vocación a ser utópico nace de una opción, brota de una persona, que es Jesús. Es decir, ningún joven consciente se consagra hoy por dedicarse a toxicómanos, o por causas de pacifismo, ni por entregarse a la causa de la liberación de la mujer, al menos exclusivamente... naturalmente que todas estas cosas pueden formar parte de los componentes, pero el elemento fundamental es porque él se siente atraído por una persona que se llama Jesús de Nazaret, el Hijo de Dios y Hombre. Y a esa persona la quiere seguir con radicalidad. Para ello es necesaria una actitud básica: la oración.

Estar prendidos de la oración. Experiencia de Dios. Como una necesidad de su vida de sacerdote, que contagia a la comunidad. Debe ser una necesidad del corazón.

Tiene la oración que asegurar el ritmo, no ser algo gravoso, como un combate que siempre tenemos que actualizar, algo entusiasmante, que deseamos. Pero la oración es también aventura; hay que aventurarse a orar, que supone una confianza en Dios mayor que la que tenemos en nuestra preparación o nuestros métodos. Se es pastor desde el

Sentirse atraído por Jesús de Nazaret

La oración como algo entusiasmante estar unidos y 'comunicados' con el Pastor. El ejemplo de Jesús que 
permanece en oración largo tiempo, sobre todo antes de los momentos cruciales de su misión, nos proporciona la muestra del talante del sacerdote. La oración -dice Mons. Uriarte- «es una gracia. Pero para ello hay que traspasar una cierta "barrera del sonido" que bastantes sacerdotes no traspasamos. Hay que lanzarse al medio de la piscina y no quedar agarrados al borde como los nadadores cómodos o medrosos» ${ }^{14}$. «La oración realizada actúa como un condicionamiento positivo que favorece el que volvamos a la oración»15

Hay que estimar la oración eso significa captar el valor vital y

Orar es abrirse al

Tú, con presencia de la comunidad existencial de esa oración. La oración es "Abrirse al Tú infinito, en comunidad". Abrir la propia persona, y no a un mensaje ni programa, sino a esa Otra persona; Dios Padre, hecho patente en Jesucristo. En la oración del sacerdote siempre está presente la comunidad. Es preciosa la presencia de la comunidad que muestra el himno de la liturgia: "Allí donde hay un cristiano/ no hay soledad, sino amor,/ pues lleva toda la Iglesia/ dentro de su corazón y dice siempre nosotros/ incluso si dice yo." Esta presencia de la comunidad en la oración del sacerdote, le prepara para encontrarse con más facilidad con la misma y capacita para el diálogo total.

Orar, simplemente, porque Dios es Dios: "No me tienes que dar porque te quiera/ porque, aunque lo que espero no esperara/ lo mismo que te quiero, te quisiera"16. Porque Dios es real y para que sea más real para nosotros cada día. Cuando interrumpimos cualquier otra actividad para entregarnos a la oración, estamos diciendo que Él es más valioso que nuestro tiempo, nuestros programas, nuestras relaciones. Estamos confesando a Dios como Primer Valor. «Nosotros oramos ante todo porque Dios es Dios, el primer Valor de nuestra vida. Oramos porque Dios es real y para que Dios resulte cada día más real para nosotros ${ }^{17}$ ».

Nuestra sociedad ha alejado a Dios de su vida o, por mejor decirlo, ha colocado en su lugar dioses que le parecen más cotidianos y

14 URIARTE, J.Ma , Ministerio presbiteral y espiritualidad, Idatz, San Sebastían, 99, p.122.

15 Ibid., p. 123.

16 LOPE DE VEGA, Sonetos.

17 URIARTE, J.Mª op.cit. pág. 125. 
manejables. El sentido de lo transcendente ha dejado paso a un sentido de lo inmediato y a Dios no se le percibe como realidad, porque se le ha querido sacar de ella y la pérdida del sentido de oración ha contribuido a esa falta de comunicación. No obstante esa necesidad queda en nosotros y Dios sigue estando ahí, al alcance de nuestra oración, sólo necesitamos abrir la puerta.

Y hacerlo desde la fe: aceptar que la oración, como fruto de la fe, participa de la esencial oscuridad de ésta. La oración aumenta nuestra sed de plenitud. San Agustín lo expresa así: "Tú estabas dentro de mí; yo estaba fuera de mí mismo. Tú estabas cerca de mí; yo estaba lejos de mí mismo". (No es algo que se superponga a la persona. Es parte de la misma persona, su aliento).

Desde la esperanza: El que espera cree que es posible lo que desea, y cree al mismo tiempo, que no puede procurárselo por sí mismo. Por eso espera. Dirá Schillebeeck: «El que espera ora, el que no ora no espera». Y cree que es posible lo que desea, porque está más allá de sus poderes. Sabe que el mundo campo de la acción del pastor, de la misión es el de su tiempo y lo acepta sin complejos y sin depresiones. Aceptar que este mundo al que vemos alejado de la creencia en Dios, superficial, fragmentado y sin deseo de un absoluto que lo unifique, embarcado en lo pequeño y cotidiano sin elevarse sobre sí para escuchar la llamada a lo que le transciende; aceptar., digo, que éste es objeto del amor de Dios y que, aun con "otro sentido de Dios", que más bien parece de un "dios" cercano, diosecillos de andar por casa, sigue necesitando de y esperando que la luz se le haga presente. Que, pese a las apariencias no tiene un gesto de desesperanza, ni una actitud negativa, porque sabe que el reino no está construido aún, que está por construir, que nos somos poseedores de la verdad, sino colaboradores con el Padre, y entonces no hacemos oración para pedir, porque lo que necesitamos es dejarnos convencer, ayudar y salvar por el Padre; confiar en que, "pese a las apariencias, Él está siempre con nosotros, haciendo todo lo posible por nuestro bien y nuestra felicidad"18.

Una cosa nos debe quedar clara: que el sacerdote no puede servir realmente a los hombres si no comparte sus condiciones de vida, tanto PO como Gaudium et Spes lo repiten continuamente. Desesperar es

Aceptar que el mundo tal como es hoy también es objeto del amor de Dios 
Superar la tentación de restauración y aceptar a Dios como actor principal fiarnos de lo que nosotros podemos hacer y no aceptar que es Dios el actor y actuante principal (¿único?) y no juzgar que la crisis puede ser de crecimiento, si de una vez nos atrevemos a llevar una profunda transformación a la luz de los documentos del Concilio, en especial de la Gaudium et Spes: «Ante el enorme dinamismo de nuestra época, ante la inusitada aceleración de la historia, ante el pluralismo enriquecedor actual hay que repensar con valentía si estamos abiertos y preparados para vivir con simultaneidad no sincronizada». Es decir, hay sacerdotes, obispos y también fieles que todavía viven como en el siglo pasado, cuando deberían vivir y coorperar con sus contemporáneos y con otras personas que, por su clarividencia, anticipan el futuro. Las autoridades eclesiásticas no han acabado de interiorizar del todo la Gaudium et Spes.

La tentación de la restauración (la mujer de Noé es un claro ejemplo de ello), la tentación de la nostalgia por los buenos viejos tiempos pasados ha bloqueado la inculturación e, incluso, la renovación bíblica. En todos los escalafones eclesiásticos, hay personas ciegas en relación con los signos de los tiempos y con un futuro que ya ha comenzado» ${ }^{19}$. Creo que no necesita comentario y sitúa con lucidez parte del problema.

Y desde la caridad pastoral. Esta caridad pastoral nos impulsa a desvivirnos y a orar por aquellos que amamos. "La visita de Dios es la caridad que es el alma de la Iglesia y que nos une a pesar de nuestras ofensas, nuestras incomprensiones y nuestras terquedades. En las personas de sus sacerdotes, Dios nos visita para que seamos perdonados y seamos capaces a su vez de perdonar nosotros, dando al mundo testimonio de amor"20. Ese amor es la presencia de Dios en la comunidad y, en especial, en los sacerdotes. Sin entrega en oración no es posible la caridad pastoral, porque «la oración es componente, requisito, consecuencia y expresión de la caridad pastoral. Componente, porque es un acto de la caridad pastoral. Requisito, porque sin ella la caridad pastoral se puede congelar y deshacer. Consecuencia, porque la caridad pastoral nos conduce a orar. Y expresión, porque en la oración se mani-

19 HÄRING, B. ¿Qué sacerdotes para hoy?, PPC. Madrid 1995, pp. 122-123.

20 LUSTIGER, J.M., Les prêtres que Dieu Donne, Desclé de Brouwer. Paris, 2000. 
fiesta la caridad pastoral»21. Muchas veces hemos visto la actividad pastoral desprovista de intercambio con lo que habíamos aprendido, o nuestra oración se hacía de tal manera intelectual, que llegaba al punto le llamar "hacer meditación" a la que considerábamos el ejemplo más 'sublime' de la oración. La experiencia espiritual, la teología y la acción pastoral se alimentan mutuamente desde su encuentro y circulación en la realidad orante del presbítero con 'cura de almas'. «La caridad pastoral nos conduce a orar. Se crea un círculo, no vicioso sino virtuoso, entre nuestra oración y la actividad inspirada por la caridad pastoral. ${ }^{22} \gg$ Introduce la circularidad entre teología, acción pastoral y experiencia espiritual. El intercambio de aire fresco proveniente de la una en las otras que renueva la teoría, la acción y la experiencia.

Esto nos lleva a preguntarnos ¿debe el sacerdote salir de su actuación en la vida cotidiana, en beneficio de la comunidad para mostrar esta oración que brota del amor a la misma?. Pastores dabo vobis nos habla de ese particular de la oración del presbítero que la hacen brotar de lo que es la misma vida. Es una oración: vinculada a la palabra. «Elemento esencial de la formación espiritual es la lectura meditada y orante de la Palabra de Dios (lectio divina); es la escucha humilde y llena de amor que se hace elocuente (...) La forma primera y fundamental de repuesta a la Palabra es la oración» (PDV, n 47, pp. 128129 , editrice Vaticana). Hay que acrecentar la sintonía con la Palabra y esa no viene si no es a través de la asiduidad no sólo en la lectura, sino en la contemplación. El sacerdote no es sólo intérprete y portavoz de la Palabra, sino que es un transmisor de la misma en la vida y con su vida, mediante ella engendra vida en la comunidad y renueva, reconforta y acompaña a los fieles. De ahí la importancia de preparar la transmisión homilética desde la contemplación anterior de la Palabra en la soledad de un nosotros comunitario en su oración de pastor.

Otro medio natural es la Liturgia de las Horas. Por medio de ella se hacen presentes todos los momentos del día en la presencia de Dios "como oración que Cristo mismo realiza en nosotros y a través de nosotros". Con el instrumento de los salmos hacemos realidad que "La oración del discípulo de Cristo no es una simple respuesta a la realidad

21 URIARTE, J-Mª opus citatum, pág 129.

22 Ibidem.

Sacerdote, transmisor de la palabra en la vida y con su vida

La caridad pastoral crea un vínculo con la actividad 
La familia eclesial reclama todo el «espacio psíquico»

Jesús no era un asceta rigorista, sus relaciones humanas estaban llenas de calor

- Nuestro celibato es del mismo cuño. Crear la familia eclesial, traspasada por la vivencia de la comunidad de Dios y la fraternidad humana constituye un motivo que nos llega tan adentro, y reclama nuestras energías hasta el punto de que no queda «espacio psíquico» para formar una familia propia y dedicarle parte de nuestras energías.

Sabiendo, por otra parte que matrimonio y celibato son complementarios, que ambos muestran aspectos del amor de Dios. Cencini habla de él como ese cantus firmus: la melodía que lleva toda la organización melódica de una pieza musical. Señalamos que el amor matrimonial es una amor real, concreto. Si es un amor imaginario se disipa pronto. El riesgo es el de ser un amor selectivo y confinado. El célibe con su vida abierta a muchos hermanos advierte de ese riesgo de exclusivismo. Pero también el casado avisa al célibe del riesgo de no amar de verdad a nadie. El amor real y el amor universal así se complementan.

Además el amor matrimonial está constituido por la demanda y la entrega. El célibe se distingue por la oblatividad, la capacidad de dar más que de recibir. (El riesgo es el de cobrar en demanda de prestigio, autoridad indiscutible).

También es el celibato una manera de compartir con aquellos que son pobres en el amor, los que no sólo carecen de bienes materiales, sino también de alguien que les ame por ellos mismos. Compartir la situación de capas especialmente humildes. En esta pobreza voluntaria del celibato que renuncia a la riqueza y al gozo de la existencia conyugal y paternal, sostiene la comunión con aquellas personas a las que les están vedadas estas alegrías, por estructura personal o situación histórica.

Y tener en cuenta que la dificultad está en mantenerse célibe para toda la vida, por el seguimiento y la dinámica del Reino.

\section{Ser pobres para ser pastores}

Vivir con austeridad en medio de esta sociedad de consumo. No estar agarrado por el afán de poseer, ser generosos y saber compartir, incluso lo poco que se tenga. No angustiarse ante las necesidades, todo esto pueden ser signos de que el sacerdote intenta llevar a la práctica 
el espíritu de pobreza que Cristo recomienda. Tres aspectos fundamentales hay en la pobreza vivida por el sacerdote:

-La pobreza como opción interior básica.

-La pobreza como comunión con los pobres.

-La pobreza como forma de hacer visible la existencia apostólica.

Como opción interior: decisión firme de poner su confianza en Dios, y en los criterios evangélicos, en las actitudes sencillas, en los medios pobres ¿Acaso no puede Dios estar diciéndonos que se acabaron las grandes parafernalias, que la fe se vive desde la sencillez y el diálogo íntimo que revierte en actitud de vida?. Importante el texto de 2 Co 12, 7-10. "La fuerza se realiza en la debilidad" (se hacer perfecta) . "Cuando estoy débil, entonces soy fuerte". Cuando siento que la debilidad se apodera de mí. Entonces entendemos que sólo Dios es Dios, sólo Jesús es Señor, sólo Jesús salva. Toda nuestra actitud es la de quien solamente trasmite al Señor que realiza la obra. Reconocemos así nuestras limitaciones (nos ven como humanos). Nos aceptamos a nosotros mismos (realista y llena de esperanza). Quitarnos la careta de la prepotencia y el poderío y mostrarnos como somos (esto acarrea problemas incluso en cuanto a respuestas vocacionales).

Como comunión con los pobres: ¿Qué pobres?

Los ricos-pobres: los que tienen todo en economía, cultura, sanidad, pero son pobres por su soledad, su edad avanzada, salud rota, fracasos...

Los pobres-ricos: tienen pocos bienes culturales, oportunidades, apoyos económicos. Tienen, no obstante una prensa, sindicatos, movimientos sociales que les apoyan.

Los pobres-pobres, los que en esta sociedad globalizada no cuentan, los excluidos. Ni siquiera son capaces de levantarse para reclamar sus derechos.

Jesús habla de todos los pobres, pero se refiere especialmente a comunión con estos últimos. La opción preferencial es por los carentes de todo, estima y posición social.

Como forma visible de existencia evangélica. La pobreza tiene que plasmarse en una forma de existencia visible, histórica, encarnada, profética, testimonial.

La pobreza económica: estilo de vida que nos sitúe entre la gente modesta. Nuestro sueldo ya nos coloca entre ellos, pese a la leyenda 
'negra e injusta' que existe aún de lo mucho que gana un cura. Cuando digo a mis amigos lo que gano y se quedan admirados, yo les digo que 'vivimos de milagro'. Importante que no nos dejemos enredar con lo poco o lo mucho. Nuestra pobreza es voluntaria, no por necesidad o carencia de cualidades para tener más.

Aceptar

hoy la

pobreza

sociológi-

ca, apostó-

lica y pro-

fética

La pobreza sociológica. No nos debe preocupar el haber bajado enteros en cuanto a la valoración y prestigio. Si los pobres nos sienten como suyos no debe importarnos. Aunque todavía no hemos llegado al extremo en cuanto a pobreza sociológica (Aún tenemos amigos que influyen y otros que nos piden que influyamos). Si algo hemos de hacer en beneficio de los demás, que sea de los más pobres.

La pobreza apostólica. Tener conciencia de que el problema del evangelio hoy, no es que sea un mensaje difícil, sino que está culturalmente devaluado. De que el mensaje de la Iglesia ya no es indiscutido; de que podemos representar 'una casa desprestigiada'.

Junto a ellas la pobreza existencial y la pobreza profética. Ver el poco enganche de llamada para los jóvenes que tenemos. Y denunciar con nuestra pobreza una llamada inhumana de vivir que lleva estos efectos:

Insensibilidad para con el sufrimiento, los derechos y las necesidades de los demás.

Arrogancia: el que tienen mucho se cree mucho;

Esclavitud: el que tienen mucho es esclavo de lo que tiene, fácilmente;

Idolatría: el que tienen mucho adora lo que tienen; lo convierte en absoluto.

Si nos libramos de esto tendremos un corazón libre y un corazón dichoso, pastoralmente preparado.

\section{Conclusión: ha de ser signo de la sociedad alternativa}

En este sentido, el cura joven, el religioso, la religiosa es testigo de una sociedad alternativa, con un sueldo o disposición libre mínima, igual al de los, de las demás; desabsolutizando el sexo, haciendo que por eil servicio a una comunidad uno renuncie a casarse y a tener su mujer/ su marido y su propia familia, atendiendo a la gente más desamparada y más pobre, criticando a la sociedad y no casándose con 
nada ni con nadie, cuando se trata de defender al pobre, los valores humanos, el Evangelio de Jesús.

Un sacerdote que es de verdad y un joven/ una joven que se consagran al servicio de los demás por seguir a Jesús, se convierten en testigos privilegiados de la sociedad alternativa. $\mathrm{Y}$, aunque muchas veces no lo demuestre con la voz muy alta, su vida misma es una contestación mansa e intrépida de esos valores inhumanos de la sociedad en

Testigos privilegiados de sociedad alternativa que vivimos.

Pero esto sólo lo entenderán aquellos que han sabido vivir su vocación de hombres desde el don, quienes, antes que nada, se han alejado de los postulados de la sociedad manipulante, quienes se sitúan desde el significado de la vida: sólo será plenamente él si se realiza en la perspectiva del darse. Nos dice el documento NVNE en el 36c.'Es la sabiduría evangélica del "gratuitamente habéis recibido, gratuitamente dad" (Mt 10, 8), enseñada por Jesús a los discípulos anunciadores de su palabra, que dice la verdad de todo ser humano: nadie podría no reconocerse en ella.

Es de esta verdad de donde la vida toma la forma que después es llamada a asumir, o es de esta figura única de la fe desde la que nacen después las diversas figuras vocacionales de la fe misma.

En definitiva, desde el compromiso cristiano, esta propuesta se convierte en "una promoción imprevista de las auténticas aspiraciones humanas y garantiza el máximo de felicidad".

Y quiero terminar con otra historia, supongo que la conocéis. Si habéis ido al Monasterio de Leyre, en Navarra habréis oído contar esta hermosa leyenda sobre lo que le aconteció a un Abad del Monasterio, en la Edad Media, que se llamaba Virila: "En un atardecer de primavera, el Abad se adentró en el bosquecillo cercano al Monasterio y quedó sorprendido por el armonioso cantar de un pajarillo. Se detuvo y se sentó un instante para escucharlo y disfrutar de tan bella melodía. Al poco, quedó de tal manera cautivado y ensimismado que perdió la noción del espacio y el tiempo. Al despertar de su arrobo y regresar al monasterio, se encontró con todo cambiado y que no conocía a nadie. Tampoco a él le conocían. La realidad era muy distinta a la que había dejado unos instantes antes, al salir de paseo. Tanto insistió que el archivero investigó sobre quién podía ser aquel monje extraño que 1lamaba a las puertas del Monasterio y descubrió una crónica en la que, 
efectivamente, se decía que cien años atrás un Abad con ese nombre había desaparecido sin dejar rastro. Había pasado un siglo y todo era distinto, tanto, que el buen Abad prefirió morir añorando el canto del pajarillo". Hasta aquí la leyenda.

Yo me pregunto si podemos quedarnos dormidos como el Abad Virila en nuestras formas ya muy experimentadas y no tendremos la sencillez de dejarnos guiar por el Señor que ama a su Iglesia, a cada una de las personas que constituyen su pueblo. La belleza divina es capaz de captar nuestra atención, pero el Padre quiere que la comuniquemos a los otros. El sacerdote del futuro se está haciendo en esa fidelidad en apertura, que es dejarse conducir por el Señor. 